\title{
ANTECEDENTS OF INFANTILE CEREBRAL PALSY
}

BY

\author{
PHILIP RAINSFORD EVANS, M.D., M.Sc., F.R.C.P.
}

(From the Department of Child Health, Guy's Hospital, and the Hospital for Sick Children, Great Ormond Street, London)

The causes of infantile cerebral palsies, and especially of diplegia, have been much argued. Collier's (1924) able discussion of diplegia shows the inconclusiveness of many of the arguments.

Before studying particular features, it seemed reasonable to survey the histories antecedent to the development of palsy obtained in a series of cases. The term ' infantile cerebral palsy' includes several syndromes, and these different conditions may have different causes. The series has, therefore, been grouped into sets of cases with similar clinical pictures. Only two of these, the spastic and the athetoid, form large enough groups for statistical study, and this paper is concerned mainly with them.

Owing to the different methods of classification used by various observers (Evans, 1948) only patients examined personally are included. Furthermore, children whose mothers were not questioned are excluded; fathers rarely have precise knowledge about the birth of their children. Information was also sought by written questionnaire from doctors or midwives in attendance at childbirth, or from hospitals or nursing homes where the patients were born. Replies were received from 80 per cent. of those questioned. The history was thus usually compiled from two sources. They were rarely contradictory. Where they were, the case was judged on the apparent merits of the two stories. The medical record was often more precise about pregnancy and labour, while the mother was almost always more circumstantial in her account of the condition of the newly born child.

About half the patients were seen in hospital and private practice, and the rest at the preliminary examination of children whose admission to a school for children with cerebral palsy was sought. The mothers of fifty children not suffering from disease of the central nervous system, seen in hospital and private practice, were questioned similarly. There may have been differences in social class between the children in the 'control group' and the patients, as no control for the children seen at the school was devised. This should be taken into account in considering such factors as parental age, size of family, and use of obstetric analgesia. The groups were balanced as to age, and all were seen within the same period of about fifteen months. Their ages varied from 1 to 13 years (average 6.4 years, standard deviation $3 \cdot 1$ ). The total number of patients was 122 . In eight the mother was not interviewed, and only the remaining 114 are considered here.

\section{Classification}

The clinical condition may be classified by reference to the distribution of the palsy and to its functional type.

The distribution is expressed in terms of the limbs affected as monoplegia, hemiplegia, paraplegia, triplegia, and tetraplegia. The last term is preferred to 'diplegia ' because this is sometimes unfortunately used in the same sense as 'paraplegia'.

On the functional side there have also been ambiguities, but there must be few cases which cannot be described as spastic, athetoid, flaccid, choreic, or ataxic.

The terms may be combined, theoretically in any combination, but in practice as spastic or flaccid paraplegia or tetraplegia. Athetosis, chorea and ataxia are usually generalized and only exceptionally need topical qualification. Hemiplegia is almost always spastic. Double hemiplegia may be a useful concept, and indeed two cases classified in this series as 'mixed type, spastic legs and athetoid arms' were probably double hemiplegias. Some of the athetoid patients might also be given the same label. For reasons indicated elsewhere (Evans, 1948) I have not considered extensor plantar responses as a criterion for taking these children out of the athetoid group.

It is often difficult to distinguish between paraplegia and mild tetraplegia. I have therefore included paraplegias and tetraplegias in the same group.

The classification of the 114 patients in this series is shown in table 1 . Nearly two-fifths were cases of spastic para- or tetraplegia and will be referred to simply as 'spastic '; a similar number of cases of athetoid tetraplegia or double athetosis will be referred to as ' athetoid.' Phelps's (1941) generalization that $\mathbf{4 0}$ per cent. of cases are spastic, $\mathbf{4 0}$ per cent. athetoid, and 20 per cent. ataxic is borne out only as far as the two major groups are concerned. 


\section{Known Carses}

Sometimes the cause of the cerebral paralysis is known, or at least appears probable from the history. This was so in seventeen of these 114 patients.

The primary conditions appeared to be:

1. Hydrocephales starting post-natally, four cases. In two of these the cause of the hydrocephalus was unknown, in two it followed meningitis. By the time the children were seen the condition did not appear to be progressing. Three of these children had spastic paraplegia. In the fourth there was athetosis, but here there was also a history of repeated asphyxial attacks during the attack of meningitis.

2. Meningitis without hydrocephalus, one case. This was a pneumococcal meningitis in a feeble baby suffering from congenital heart disease. Intrathecal penicillin and saline lavage to remove a spinal block were part of the treatment. This child had hemiplegia.

\section{TARUE 1}

CLINICAL CLASSIFICATION OF 114 CHILDREN SUFFERING FROM CEREBRAL PALSY

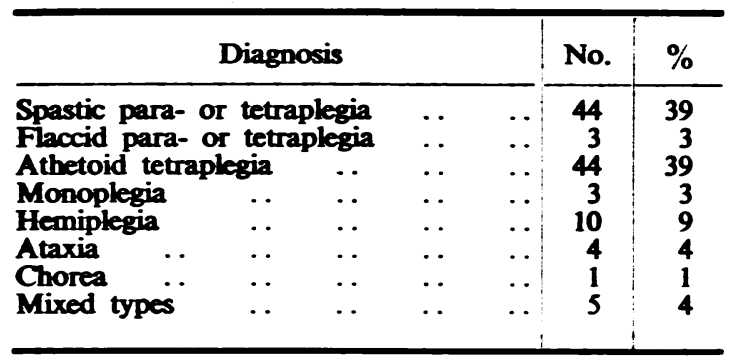

3. Excephalitis, two cases. Illnesses diagnosed as polioencephalitis at ten months and measles encephalitis at four years preceded spastic tetraplegia and athetosis in these two children.

4. Haemontagic disense of the newborn, two cases. One may doubt whether intracranial haemorrhage caused the nervous lesions in these cases, but it seems unreasonable to leave them in the group, to be discussed later, in which there was no obvious cause. One child had left hemiplegia with right optic atrophy. In the other child haemorrhagic disease was associated with severe asphyxia; generalized athetosis later became apparent.

5. Erythroblastosis foetalis, eight cases. The association between Rhesus-group incompatibility and kernicterus is well known. In these cases the diagnosis was made in the neonatal period and was confirmed retrospectively. In two the mother's blood was not investigated. Each of the other six was Rhesus-negative. In three the indirect CoombsMourant-Race test was also done. It was positive in two. In one a year had elapsed since the birth of the affected child. The other was five years old; but the mother had had another baby, suffering from icterus gravis, one month before the test was done. In the third case the test was negative but six years had passed since the last (and affected) child was born.

The neurological condition in four of these children was athetoid, and in one choreic; one was classified as ataxia. The other two were atonic and tetraplegic, but they were only a year old and the ultimate diagnosis is doubtful.

One must consider the possibility that, in other cases in which erythroblastosis was not diagnosed, Rhesus-incompatibility may have been the cause of the palsy. Bakwin and Wiener's (1947) investigation of the blood groups of twenty-three athetoid children and their mothers makes this hypothesis seem unlikely to be true.

Dr. I. A. B. Cathie kindly carried out indirect Coombs-Mourant-Race tests on thirty-eight of the mothers of palsied children who had not had icterus gravis, selected because they lived in London. The result was negative in every case. In twenty-eight of them Rhesus grouping was also done; twenty-six were $R$ h-positive. The affected children of the two Rh-negative mothers were first-born. One may conclude that occult Rhesus incompatibility is not a common cause of cerebral palsy.

Conclusions: Known Causes of Cerebral Palsy

1. Hydrocephalus, severe meningitis, encephalitis, and possibly intracranial haemorrhage due to haemorrhagic disease of the newborn appeared occasionally in this group as causes of cerebral palsy.

2. Erythroblastosis foetalis due to Rhesus incompatibility is about as common as all the other known causes put together.

3. Altogether, these 'known causes' accounted for the disease in only 15 per cent. of the patients.

\section{Family History}

The rest of this paper is (except where otherwise stated) concerned only with the cases due to ' unknown causes,' and of them only with cases of spastic para- or tetraplegia and of athetosis. Each of these two groups contained thirty-eight patients.

- Hereditary spastic paraplegia appears to be extremely rare in this country ' (Bell and Carmichael, 1939). In the whole series of 114 cases there was no history of infantile cerebral palsy in the grandparents, parents, uncles, or aunts of the patients. One microcephalic hemiplegic boy had a microcephalic tetraplegic brother. The other members of the families were not examined for evidence of incipient or slight paralysis, but it appears that heredity is not commonly an important influence in producing the disease.

Consanguinity of the parents was discovered in one case of spastic paraplegia and in one of the control 
cases. This case of spastic paraplegia also provided the only example of a developmental anomaly unrelated to the nervous system or special senses: the child had only four lumbar vertebrae.

Two siblings of patients had developmental anomalies: a cranial deficiency of some sort in one case, and spina bifida and mental defect in another. Two siblings of control children may have had congenital anomalies, congenital heart disease in one case and epilepsy with mental defect and a big head in the other.

Sex. A surprising number of athetoid children were boys (table 2), but this may have been a chance finding.*

TABLE 2

SEX OF PATIENTS

\begin{tabular}{ll|c|c|c}
\hline \multicolumn{1}{r|}{ Sex } & & Spastic 38 & Athetoid 38 & Control 50 \\
\cline { 1 - 4 } Male & $\cdots$ & 19 & 24 & 26 \\
Female & $\cdots$ & 19 & 15 & 24 \\
\hline
\end{tabular}

TABLE 3

\section{AGE OF PARENTS AT TIME OF BIRTH OF AFFECTED CHILD}

\begin{tabular}{|c|c|c|c|c|c|}
\hline \multirow{2}{*}{ Group } & & \multicolumn{2}{|c|}{ Age of father } & \multicolumn{2}{|c|}{ Age of mother } \\
\hline & & Average & S.D. & Average & S.D. \\
\hline $\begin{array}{l}\text { Spastic } 38 \\
\text { Athetoid } 38 \\
\text { Control } 50\end{array}$ & $\begin{array}{l}\cdots \\
\cdots \\
\cdots\end{array}$ & $\begin{array}{l}34 \\
33 \\
32\end{array}$ & $\begin{array}{l}5 \cdot 6 \\
5 \cdot 1 \\
6 \cdot 8\end{array}$ & $\begin{array}{l}31 \\
30 \\
31\end{array}$ & $\begin{array}{l}5 \cdot 0 \\
4 \cdot 9 \\
4 \cdot 9\end{array}$ \\
\hline
\end{tabular}

TABLE 4.

NUMBER OF PREGNANCIES AND NUMBER OF LIVE BIRTHS IN MOTHERS OF SPASTIC, ATHETOID, AND CONTROL PATIENTS

\begin{tabular}{|c|c|c|c|c|c|c|}
\hline & \multicolumn{2}{|c|}{ Spastic 38} & \multicolumn{2}{|c|}{ Athetoid 38} & \multicolumn{2}{|c|}{ Control so } \\
\hline & Total & $\overline{\text { Average }}$ & Total & $\overline{\text { Average }}$ & Total & Average \\
\hline $\begin{array}{l}\text { Pregnancies } \\
\text { Live births }\end{array}$ & $\begin{array}{l}91 \\
80\end{array}$ & $\begin{array}{l}2 \cdot 4 \\
2 \cdot 1\end{array}$ & $\begin{array}{l}85 \\
70\end{array}$ & $\begin{array}{l}2 \cdot 2 \\
1 \cdot 8\end{array}$ & $\begin{array}{l}130 \\
123\end{array}$ & $\begin{array}{l}2 \cdot 6 \\
2 \cdot 5\end{array}$ \\
\hline
\end{tabular}

Parental age (table 3). The age of the parents was similar in the three comparable groups of spastic, athetoid, and control children.

Pregnancies and live births. The average numbers of times the mother had been pregnant at the time of observation are shown in table 4 . The differences tetween the three groups are slight, and as this fartor is much affected by social status it would be unwise to pay attention to them.

* I am indebted to Dr. P. E. Polani for the statistical treatment of the information in tables $2,4,5,7,8,10$, and 11 . The $\chi^{2}$ test was used as the main test of significance. It was assumed that values of P (probability) of less than 0.05 were not likely to have arisen by chance. The standard error of the difference between proportions was considered not likety to be significant if it exceeded twice the standard error.
TABLE 5

ONLY CHILDREN AND SINGLE PREGNANCIES

\begin{tabular}{|c|c|c|c|c|c|}
\hline \multirow{2}{*}{ Group } & & \multicolumn{2}{|c|}{$\begin{array}{l}\text { Only surviving } \\
\text { child }\end{array}$} & \multicolumn{2}{|c|}{$\begin{array}{l}\text { Only one } \\
\text { pregnancy }\end{array}$} \\
\hline & & No. & $\%$ & No. & $\%$ \\
\hline $\begin{array}{l}\text { Spastic } 38 \\
\text { Athetoid } 38 \\
\text { Control } 50\end{array}$ & $\begin{array}{l}\cdots \\
\cdots \\
\cdots\end{array}$ & $\begin{array}{l}14 \\
14 \\
12\end{array}$ & $\begin{array}{l}36 \\
36 \\
24\end{array}$ & $\begin{array}{l}13 \\
11 \\
10\end{array}$ & $\begin{array}{l}34 \\
29 \\
20\end{array}$ \\
\hline
\end{tabular}

The number of live children produced in relation to the number of pregnancies is less affected by this consideration, and comparisons of the athetoid and control figures $(P=<0.01)$ indicates that there may at times be a lethal agent affecting the foetus in families producing athetoid children. The differences between athetoid and spastic $(P=0.5)$ and spastic and control $(P=>0 \cdot 1)$ are less impressive.

One-child sterility (table 5). One might expect to find a high proportion of only children in the affected families, because these children need much maternal care, or possibly even because of some lack of fecundity. These conditions are affected by social state, and the differences shown in this series are inconsiderable.

Abortions (table 6). The number of abortions in the families of the patients did not differ significantly from that in the control families.

Birth rank (position in family) (table 7). The position of the affected child in the family, expressed as the number of the pregnancy which produced him, and not as his place among surviving children, is shown in table 7. The difference between the number of first-born children in spastic and control groups may well be due to chance, but the difference between athetoid and control is very unlikely to be fortuitous.

Of athetoid children 79 per cent. were firstborn, of controls only 44 per cent. The mother of an athetoid child is unlikely to have a healthy child before she has one who develops athetosis, except in the special case of kernicterus. She actually did so in only four of the thirty-eight instances in this

TABLE 6

NUMBER OF ABORTIONS IN SPASTIC, ATHETOID, AND CONTROL PATIENTS

\begin{tabular}{l|c|cccc}
\hline \multirow{2}{*}{ Group } & \multicolumn{4}{c}{ Abortions } \\
\cline { 2 - 6 } & $\begin{array}{c}\text { Before } \\
\text { patient's } \\
\text { birth }\end{array}$ & $\begin{array}{c}\text { After } \\
\text { patient's } \\
\text { birth }\end{array}$ & Total & $\%$ \\
\hline Spastic 38 38 & $\cdots$ & 6 & 4 & 10 & 26 \\
Athetoid 38 & $\cdots$ & 2 & 7 & 9 & 23 \\
Control 50 & $\cdots$ & 3 & 5 & 8 & 16 \\
\hline
\end{tabular}


TABLE 7

BIRTH RANK

\begin{tabular}{|c|c|c|c|c|c|c|}
\hline \multirow{2}{*}{$\begin{array}{l}\text { Number of } \\
\text { pregnancy }\end{array}$} & \multicolumn{2}{|c|}{ Spastic } & \multicolumn{2}{|c|}{ Athetoid } & \multicolumn{2}{|c|}{ Control } \\
\hline & No. & $\%$ & No. & $\%$ & No. & 。 \\
\hline $\begin{array}{c}1 \\
2 \\
3 \\
4 \\
5 \\
6 \\
7 \\
\text { Unknown }\end{array}$ & $\begin{array}{r}21 \\
4 \\
7 \\
2 \\
3 \\
0 \\
0 \\
1\end{array}$ & $\begin{array}{r}56 \\
11 \\
19 \\
5 \\
8\end{array}$ & $\begin{array}{r}30 \\
5 \\
1 \\
2 \\
0 \\
0 \\
0 \\
0\end{array}$ & $\begin{array}{r}80 \\
13 \\
3 \\
5\end{array}$ & $\begin{array}{r}22 \\
13 \\
11 \\
1 \\
1 \\
1 \\
1 \\
0\end{array}$ & $\begin{array}{r}44 \\
26 \\
22 \\
2 \\
2 \\
2 \\
2\end{array}$ \\
\hline Total & 38 & & 38 & & 50 & \\
\hline
\end{tabular}

* Of thirty-seven cases.

series, for in the eight cases in which the child was not the result of the first pregnancy abortions preceded the birth of the affected child in two, one child died twenty-four hours after birth, and another has spina bifida (treated surgically) and mental defect.

Twinning. It is noteworthy that six of these seventy-six cases of cerebral palsy of obscure etiology were twins (table 8), while there were no examples of twins in the fifty controls or their siblings, or in the siblings of the affected children. The numbers are small and may have occurred by chance, but the proportion, particularly in spastics, suggests the need for study in a larger group. Bakwin and Wiener (1947) note twin births in three of twenty-three cases of athetosis.

The twin siblings of the two athetoid patients were healthy, but, of the four twin siblings of spastics, two were stillborn macerated foetuses, and one died on the first day of life, while the fourth was healthy.

\section{CONClusions: Family History}

1. The following factors appear not to be commonly associated with the production of spastic or athetoid cerebral palsy: a family history of the disease; parental consanguinity; parental age.

2. Birth-order is unimportant in spastic children.

3. Other factors which were not demonstrated in this survey to be associated with the production

TABLE 8.

TWINS

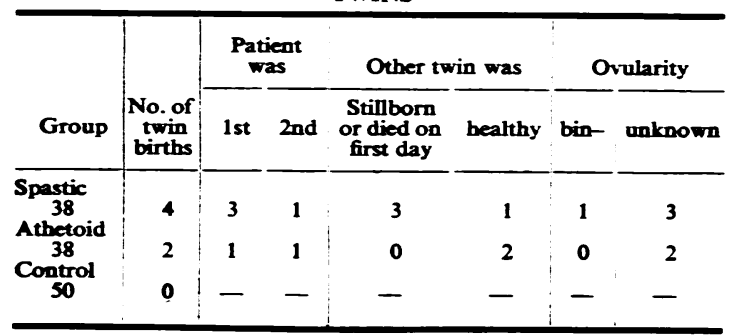

TABue 9

ILL HEALTH DURING PREGNANCY

\begin{tabular}{|c|c|c|c|c|}
\hline \multicolumn{2}{|l|}{ Condition } & Spastic 38 & Athetoid 38 & Control 50 \\
\hline \multicolumn{2}{|c|}{$\begin{array}{l}\text { Threatened abortion } \\
\text { Albuminuria alone } \\
\text { Toxaemia . . } \\
\text { Prolonged vomiting } \\
\text { Pyelitis .. }\end{array}$} & $\begin{array}{l}3 \\
1 \\
1 \\
1 \\
0 \\
3\end{array}$ & $\begin{array}{l}5 \\
2 \\
2 \\
4 \\
0 \\
1\end{array}$ & $\begin{array}{l}4 \\
0 \\
2 \\
2 \\
2 \\
2\end{array}$ \\
\hline $\begin{array}{c}\text { Total diseases } \\
\text { Total mothers } \\
\text { affected }\end{array}$ & $\cdots$ & 9 & 14 & $\begin{array}{l}12 \\
10\end{array}$ \\
\hline
\end{tabular}

of spastic or athetoid palsy, although there was some suggestion from the figures that they might be worth more extended investigation were: the mother having no pregnancies apart from that producing the affected child; the number of abortions; twinning in association with the disease.

4. The mothers of spastic patients had rather few living children, but this was not shown to be significant.

5. The following factors appeared to be associated with the production of athetoid palsy: primogeniture; the rather small number of living children born to the mothers of these children.

\section{Health During Pregnancy}

In view of the frequency of premature birth in the palsied group it is rather surprising to find that there was no strikingly increased incidence of ill-health

TABLE 10

BIRTH WEIGHTS

Weight

lb. and oz. Kg. Spastic 38 Athetoid 38 Control 50

\begin{tabular}{|c|c|c|c|c|}
\hline \begin{tabular}{l}
\multicolumn{2}{c}{$<-8$} \\
$1-9$ to $2-8$ \\
$2-9$ to $3-8$ \\
$3-9$ to $4-8$ \\
$4-9$ to $5-8$
\end{tabular} & $\begin{array}{c}<0 \cdot 7 \\
0 \cdot 8-1 \cdot 2 \\
1 \cdot 3-1 \cdot 6 \\
1 \cdot 7-2 \cdot 0 \\
2 \cdot 1-2 \cdot 5\end{array}$ & $\begin{array}{l}1 \\
2 \\
2 \\
9 \\
4\end{array}$ & $\begin{array}{l}0 \\
2 \\
3 \\
2 \\
5\end{array}$ & $\begin{array}{l}\mathbf{0} \\
\mathbf{0} \\
\mathbf{0} \\
1 \\
\mathbf{3}\end{array}$ \\
\hline $\begin{array}{l}5-9 \text { to } 6-8 \\
6-9 \text { to } 7-8 \\
7-9 \text { to } 8-8 \\
8-9 \text { to } 9-8 \\
9-9 \text { to } 10-8 \\
>10-8\end{array}$ & $\begin{array}{l}2 \cdot 6-2 \cdot 9 \\
3 \cdot 0-3 \cdot 4 \\
3 \cdot 5-3 \cdot 8 \\
3 \cdot 9-4 \cdot 3 \\
4 \cdot 4-4 \cdot 8 \\
>4 \cdot 8\end{array}$ & $\begin{array}{l}6 \\
9 \\
3 \\
0 \\
1 \\
1\end{array}$ & $\begin{array}{r}7 \\
12 \\
3 \\
2 \\
0 \\
0\end{array}$ & $\begin{array}{r}7 \\
14 \\
10 \\
8 \\
0 \\
0\end{array}$ \\
\hline \multicolumn{2}{|c|}{$\begin{array}{c}\text { Unknown but } \\
\text { mature } \\
\text { Unknown but } \\
\text { premature }\end{array}$} & $\begin{array}{l}0 \\
1\end{array}$ & $\begin{array}{l}1 \\
0\end{array}$ & $\begin{array}{l}2 \\
0\end{array}$ \\
\hline $\begin{array}{l}\text { Avera } \\
\text { S.D. }\end{array}$ & . & $\begin{array}{c}5 \mathrm{lb} .6 \mathrm{oz} \\
2.04\end{array}$ & $\begin{array}{c}6 \mathrm{lb} .0 \mathrm{oz} \\
1.87\end{array}$ & $\begin{array}{l}7 \mathrm{lb} .8 \mathrm{oz} . \\
1.46\end{array}$ \\
\hline
\end{tabular}


during pregnancy in the mothers of affected children (table 9).

\section{Inmaturity (Birth Weight)}

Because of the uncertainty of estimates of the duration of pregnancy the birth weight was adopted as a measure of immaturity. A baby weighing $5 \frac{1}{2} \mathrm{lb}$. $(2,500 \mathrm{~g}$.) or less was considered to be immature (table 10). The number of them in the control group was proportionate to that in the general population (Crosse, 1945). There is a significant increase in the number of premature infants among the patients compared with the controls. This is especially noticeable in the spastic group, but the difference between spastic and athetoid may be due to chance. So may the double peak in the distribution of birth weights of the spastic children.

\section{Labour}

In table 11 are shown some of the conditions occurring at parturition. Information about them is inprecise in some (for example, duration of labour) and precise in others (for example, instrumental

TABUE 11

COMPLICATIONS OF LABOUR

\begin{tabular}{|c|c|c|c|}
\hline & Spastic 38 & Athetoid 38 & Control 50 \\
\hline 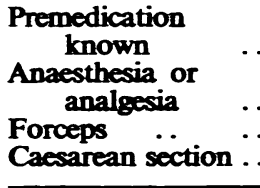 & $\begin{array}{l}3 \\
17(45 \%) \\
6(16 \%) \\
0\end{array}$ & $\begin{array}{c}6 \\
33(87 \%) \\
15(40 \%) \\
1\end{array}$ & $\begin{array}{l}4 \\
19(38 \%) \\
5(10 \%) \\
0\end{array}$ \\
\hline $\begin{array}{r}\text { Presentation-vertex } \\
\text { breech } \\
\text { face . }\end{array}$ & $\begin{array}{r}36 \\
2 \\
0\end{array}$ & $\begin{array}{r}37 \\
2 \\
0 \\
\end{array}$ & $\begin{array}{r}47 \\
2 \\
1\end{array}$ \\
\hline $\begin{array}{l}\text { Placenta praevia } \\
\text { Inertia . } \\
\text { Prolapsed cord } \\
\text { 'Dry labour' } \\
\text { Eclampsia .. }\end{array}$ & $\begin{array}{l}\mathbf{1} \\
0 \\
0 \\
0 \\
0 \\
0\end{array}$ & $\begin{array}{l}2 \\
1 \\
2 \\
1 \\
0\end{array}$ & $\begin{array}{l}\mathbf{0} \\
\mathbf{0} \\
\mathbf{0} \\
\mathbf{0} \\
\mathbf{0}\end{array}$ \\
\hline $\begin{array}{l}\text { Labour : } \\
\text { precipitate } \\
\text { lasting more } \\
\text { than } 12 \text { hours }\end{array}$ & $\begin{array}{r}3 \\
13\end{array}$ & $\begin{array}{r}2 \\
14\end{array}$ & $\begin{array}{r}3 \\
12\end{array}$ \\
\hline
\end{tabular}

delivery), but there seems to be little difference between the three groups except with respect to the use of anaesthetics and of forceps, which was much more frequent at the births of athetoid children than in the other cases.

\section{Neomatal Condition}

For a description of the neonatal condition it was usually necessary to depend on the mothers' accounts. Specific enquiries were made about blue and white asphyxia, efforts at resuscitation, inefficiency in sucking or convulsions in the first two weeks of life, birth palsy, and external signs of injury (table 12). Resuscitation need not be considered separately from asphyxia, and the figures for blue and white asphyxia have been combined.

There is a great difference in the incidence of neonatal asphyxia in the athetoid and the control groups. Asphyxia was in most cases prolonged, for example, 'blue for twenty-four hours,' ' atelectasis and cerebral symptoms for three weeks, not expected to live,' ' dead two and a half hours, then she moved so the doctor sent her to hospital,' 'white asphyxia for twenty-four hours, in oxygen tent five days," "strung up by the feet for forty-eight hours as she'd so much in her lungs she cuuldn't breathe,' 'breathing two or three times a minute for a long time.' In four cases there was apparently no early asphyxia, but a history of attacks of collapse and cyanosis starting between the third and the tenth day.

There was only one athetoid case without a history of asphyxia. He was the fourth child of healthy Rh-positive parents. The first two children were healthy, the third was said to be jaundiced at birth but the jaundice soon faded. The patient, the fourth child, was also jaundiced at birth, and although he was born at full term and weighed eight pounds he was thought to have remained yellow for about four months. If he is really an

TARUE 12

NEONATAL CONDITIONS (FIGURES IN BRACKETS REFER TO MATURE CHILDREN ONLY)

\begin{tabular}{|c|c|c|c|}
\hline Feature & $\begin{array}{l}\text { Spastic } \\
38(20)\end{array}$ & $\begin{array}{c}\text { Athetoid } \\
38 \text { (28) }\end{array}$ & $\begin{array}{l}\text { Control } \\
50(48)\end{array}$ \\
\hline $\begin{array}{l}\text { Asphyxia .. } \\
\text { Resuscitation } \\
\text { Inefficient sucking } \\
\text { Convulsions } \\
\begin{array}{l}\text { External injury } \\
\text { Palsy (facial or } \\
\text { brachial) }\end{array} \\
\text { b }\end{array}$ & $\begin{array}{r}8(3) \\
5(1) \\
14(6) \\
2(1) \\
1(0) \\
2(0)\end{array}$ & $\begin{array}{l}37(27) \\
16(13) \\
30(23) \\
8(5) \\
6(5) \\
2(2)\end{array}$ & $\begin{array}{l}0(0) \\
0(0) \\
3 \quad(3) \\
0(0) \\
0(0) \\
0(0)\end{array}$ \\
\hline
\end{tabular}

example of the effects of kernicterus, then one may say that every athetoid child had suffered from icterus gravis neonatorum or asphyxia, except in the case in which there was a history of measles encephalitis.

The difference in the incidence of asphyxia in these two groups is apparent even if premature babies are omitted. This is true also for difficulty in sucking, convulsions, and external signs of injury.

When spastic and control are compared we find a significantly increased incidence of asphyxia and difficulty in sucking, but this is not evident if premature babies are excluded. Convulsions and injury were uncommon in the spastic cases.

Comparing spastic and athetoid infants, there is a significantly increased incidence among the latter of 
asphyxia and of inefficiency in sucking. This conclusion is unaffected by exclusion of the premature infants. The difference in incidence of convulsions and of external injury was probably not significant.

\section{Discussion}

The histories of these patients were surveyed in the hope that profitable lines for further investigation might be discovered. A detailed review of the etiology and pathology of cerebral palsy would be out of place here, but some conceptions of the subject may be mentioned.

Little noted in 1843, and stressed in 1862, the coincidence of "abnormal parturition, difficult labours, premature birth, and asphyxia neonatorum ' with cerebral palsy. McNutt attached importance to meningeal haemorrhage, Brissaud to prematurity. These early concepts were severely criticized by Freud (1897) and Collier (1899, 1924), who considered that agenesis of cerebral neurones, caused by some unknown noxious influence which was only exceptionally hereditary, was the essential lesion. Collier's views have been widely accepted in this country, but it should be noted that he was investigating 'cerebral diplegia.' Little was discussing a variety of 'deformities.' Classification is difficult owing to changes in terminology, but if we consider (for example) the incidence of neonatal asphyxia in Little's cases, we find that it occurred in: seven of sixteen cases of symmetrical spastic paralysis (cerebral diplegia and paraplegia); eight of nine cases of asymmetrical spastic paralysis (? double hemiplegia); every one of eight cases of hemiplegia; every one of seven cases with irregular movements, probably athetoid. Collier's conclusions apply to cerebral diplegia, but are often referred to cerebral palsy in general.

It seems reasonable to try to classify the various types of cerebral palsy and to investigate their etiology separately. Phelps (1938) suggests that spastic paralysis is produced by cortical damage - which most frequently results from malplaced or too tightly placed forceps,' and athetosis by injury to the base of the brain 'as a result of too strong traction and stretching of the neck.' While approving the division one cannot applaud the conclusion about spastic paralysis, in which the forceps rate was only 16 per cent. in my cases (table 11). Brockway's (1936) division by distribution of paralysis does not appear to be helpful, but McGovern and Yannet's (1947) consideration of mentally defective adult patients shows that primogeniture and abnormal delivery are associated with asymmetrical cerebral palsy, and not with symmetrical diplegia and paraplegia. Wyllie (1943) is convinced, as a result of twenty years' observation, that the percentage of abnormal and difficult births is much greater in cases of bilateral hemiplegia, often with athetosis, than in those of spastic tetraplegia.

The series recorded here provided two groups large enough for comparison, one consisting of more or less symmetrical paraplegias and tetraplegias, the other of cases of double athetosis.

The spastic cases were associated with hydrocephalus and encephalitis, but much more often no cause of the condition was apparent. Family history, sex, parental age, birth order, parental fertility, and liability to abortion were not shown to be significant. Similarly there was no important increase in ill-health during pregnancy or in abnormalities of labour. Immaturity on the other hand was extremely common, and probably caused the feeding difficulties and asphyxial troubles which often occurred in the neonatal period. Immaturity is much commoner in these cases than in the athetoid group or in children with congenital malformations in general (Murphy, 1947), and demands investigation. For the moment we must accept Collier's (1924) poetico-pathological concept of 'the garden in early spring well sown with seeds - the neuroblasts' subject to a 'noxious influence -a sudden frost for example,' but alas only for example as we are unaware of its nature

The problem of the genesis of double athetosis holds better promise of solution. Here again family history, parental age, and history of ill-health in pregnancy are negligible, while data on sex incidence, fertility, and abortion are inconclusive. There are, however, indications that damage produced by difficult labour is significant in some way. Primogeniture and the use of anaesthesia and the forceps were common in this group, while a history of asphyxia constantly occurred in the cases not characterized by neonatal jaundice. Bakwin and Wiener (1947) made similar observations. Asphyxia produces cerebral damage but may, of course, itself be the result of intracranial injury. Further study of the mechanisms at work is likely to be fruitful. Various investigators (for example Courville, 1936; Thorner and Lewy, 1940) have demonstrated that asphyxia produces 'areas of devastation' in the brain, but it is far from certain that this is the operative process in these cases. Denny-Brown's (1946) conclusion about the genesis of status marmoratus, that: 'Its relationship to asphyxia neonatorum, as maintained by the Vogts, is as untenable as the supposed causal relationship between asphyxia and Little's disease,' is the latest but not the last word on the subject.

\section{Sumnary}

1. In 114 cases of cerebral palsy the history was obtained from the mother. Further information was obtained in 80 per cent. from the mother's attendant at the birth of the affected child.

2. The causes of the condition in seventeen cases appeared to be hydrocephalus (four), meningitis (one), non-suppurative encephalitis (two), possibly haemorrhagic disease of the newborn (two), and nuclear damage due to erythroblastosis foetalis (eight). 
3. The remaining ninety-seven cases included thirty-eight of spastic paraplegia or tetraplegia and thirty-eight of double athetosis.

4. In the thirty-eight spastic cases a family history of the disease, parental consanguinity, sex, parental age, birth order, maternal health during pregnancy, and abnormalities of labour did not appear to be important. There was no indisputable evidence of infertility, frequent abortion, or frequent twinning in the parents of these children. Premature birth was very common in these cases.

5. In the thirty-eight athetoid cases a family history of the disease, parental consanguinity, parental age, and maternal health during pregnancy did not appear to be important.

No clear evidence was obtained of an increased incidence in males, parental infertility, unusually frequent abortion, or twinning.

In these athetoid cases primogeniture was common and the mothers had rather few living children. Prematurity was unusually common, but not to the same degree as in spastic cases. Obstetric analgesia, forceps deliveries, neonatal asphyxia, convulsions, and difficulty in feeding were common. Taken together, these features suggest an association between difficult labour and the development of double athetosis.

The conditions encountered in this survey suggest three/ particular lines of approach to comprehension of the genesis of cerebral palsy:

1. Close clinical and pathological investigation of individual types of cerebral palsy, rather than of 'Little's Disease ' in general.

2. Elucidation of the mechanism of damage to the nervous system in conditions in which the cause is known, for example hydrocephalus, Rhesus incompatibility.

3. Experimental work on the effect of asphyxia, and of venous and arterial lesions, on the immature central nervous system.

I am deeply grateful to many doctors and midwives who answered my questionnaire; to Dr. E. B. Dawe for collecting specimens of blood and to Dr. I. A. B. Cathie for testing them; to Dr. P. E. Polani for statistical help; to the Board of St. Margaret's School, Croydon, where many of the patients were seen; and to the Trustees of the National Birthday Trust Fund for paying the expenses of the investigation.

\section{REFERENCES}

Bakwin, H., and Wiener, A. S. (1947). J. Pediat., 30, 64. Bell, J., and Carmichael, E. A. (1939). Treasury of Human Inheritance, vol. 4, part 3, 168 . London.

Brockway, A. (1936). J. Amer. med. Ass., 106, 1635.

Collier, J. S. (1899). Brain, 22, 373. (1924). Ibid., 47, 1; and Proc. R. Soc. Med., 17, Section of Neurology, 1.

Courville, C. B. (1936). Medicine, 15, 129.

Crosse, V. M. (1945). The Premature Baby. London.

Denny-Brown, D. (1946). Diseases of the Basal Ganglia and Subthalamic Nuclei. New York.

Evans, P. R. (1948). Proc. R. Soc. Med., 41, 402.

Freud, S. (1897). Spec. Path. Ther. Nothnagel, 9, 6. Vienna.

Little, W. J. (1843). Lancet, 1, 319.

(1862). Obstet. Trans., 3, 293.

McGovern, J., and Yannet, H. (1947). Amer. J. Dis. Child., 74, 121.

Murphy, D. P. (1947). Congenital Malformations. Second Edit. Philadelphia, London, and Montreal.

Phelps, W. M. (1938). J. Amer. med. Ass., 111, 1. (1941). South. med. J., 34, 770.

Thorner, M. W., and Lewy, F. H. (1940). J. Amer. med. Ass., 115, 1595.

Wyllie, W. G. (1943). Unpublished. 